\title{
Pengukuran Ketinggian Permukaan Air Sungai menggunakan Prinsip Tekanan Berbasis Mikrokontroler ATMega328
}

\author{
Bachtera Indarto, ${ }^{*}$ Hasto Sunarno, Muhammad Fahrudin, dan Didiek B. Rahmat \\ Jurusan Fisika, Fakultas Matematika dan Ilmu Pengetahuan Alam, \\ Institut Teknologi Sepuluh Nopember (ITS), Kampus ITS Sukolilo, Surabaya 60111
}

Intisari

\begin{abstract}
Telah dilakukan pembuatan alat ukur ketinggian permukaan air sungai menggunakan prinsip tekanan berbasis mikrokontroler Atmega328. Besaran ketinggian permukaan air sebanding dengan tekanan di dalam air tersebut diubah menjadi besaran tekanan dengan menggunakan pipa transmiter yang didalamnya terdapat sensor tekanan BMP085. Data diolah dengan menggunakan mikrokontroler ATMega382, yang kemudian ditampilkan pada liquid crystal display $(\mathrm{LCD}) 16 \times 2$. Berdasarkan penelitian yang telah dilakukan, pipa transmitter tersebut dapat digunakan mengukur ketinggian permukaan air dengan menggunakan prinsip tekanan. Sensor tekanan BMP085 dan pipa transmitter yang dirancang mampu digunakan dengan baik dengan berdasarkan pada faktor kalibrasi: Level $=(11,52 \times$ Tekanan -11612$) \mathrm{mm}$. Ketika pengujian sistem, ketinggian permukaan air pasang di pintu air kali Wonorejo, Surabaya dapat diamati dengan faktor koreksi: Level $=(11,47 \times$ Tekanan -10149$)$ $\mathrm{mm}$.
\end{abstract}

\begin{abstract}
Measuring tools water level of theriver using ATmega328 microcontroller-based pressure principle has been made. The amount of water level proportional to the pressure in the water is converted into pressure transmitter using a pipe in which there is a pressure sensor BMP085. Data were processed using ATMega382 microcontroller, which is then displayed on a liquid crystal display (LCD) $16 \times 2$. Based on the research that has been done, the transmitter pipe can be used to measure the height of the water surface by using the principle of pressure. BMP085 pressure sensor and transmitter that is designed pipe is able to be used properly with based on the calibration factors: Level $=(11.52 \times$ pressure -11612$) \mathrm{mm}$.. When testing the system, the water level in the tidal riversluice Wonorejo, Surabaya can be observed by a correction factor: Level $=(11.47 \times$ pressure -10149$)$ $\mathrm{mm}$.
\end{abstract}

KATA KUNCI: pressure principle, level measurement, high water level

\section{PENDAHULUAN}

Air merupakan elemen utama yang ada di bumi. Sebagian besar $(71 \%)$ dari permukaan bumi tertutup oleh air. Sekalipun jumlah air relatif konstan, tetapi air tidak diam melainkan bersirkulasi setiap saat. Air berperan penting dalam ekosistem lingkungan dan kehidupan manusia, air digunakan dalam kehidupan sehari-hari untuk keperluan rumah tangga sampai dengan industri. Air tersebut dapat berasal dari air laut, air tanah, air danau atau air sungai. Jumlah ketersedian air yang dibutuhkan oleh indutri maupun masyarakat umum harus tetap terjaga ketersediaanya dan sehingga dapat tercukupi dengan baik. Karena ketersediaan air dapat mempengaruhi proses produksi (pada industri) dan proses kehidupan sehari-hari. Untuk mengetahui jumlah ketersediaan air tersebut, diperlukannya suatu alat yang dapat mengukur level (ketinggian permukaan) air. Perancangan dan pengukuran level

${ }^{*}$ E-MAIL: bachteraephysics.its.ac.id air dilakukan agar mudah dalam melakukan pengukuran dan pengamatan ketinggian air secara langsung setiap saat [1].

Setiap alat ukur instrument yang dipergunakan untuk mengukur dan menunjukkan tinggi dari permukaan cairan disebut sebagai alat ukur level (ketinggian permukaan air). Pengukuran tinggi permukaan cairan dilakukan dengan memasang beberapa peralatan yang berbentuk kolom seperti tangki, drum, maupun tabung silinder.

Berdasarkan alat ukurnya, pengukuran dapat dilakukan dengan cara langsung dan tidak langsung. Pengukuran langsung bila pengukuran memiliki pembanding yang standar, yaitu pengukuran yang mempunyai nilai standar, misalnya ukuran panjang dan berat. Sedangkan pengukuran tidak langsung bila pembandingnya adalah suatu yang telah dikalibrasikan terhadap besaran standar.

Tekanan di sembarang titik dalam zat cair adalah perbandingan gaya normal $\mathrm{dF}$ yang bekerja pada suatu luasan kecil pada titik itu, terhadap luas dA:

$$
p=\frac{d F}{d A}
$$




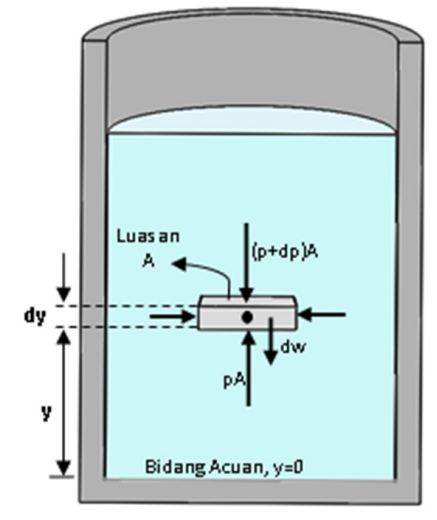

Gambar 1: Gaya pada elemenzat cair dalam kesetimbangan.

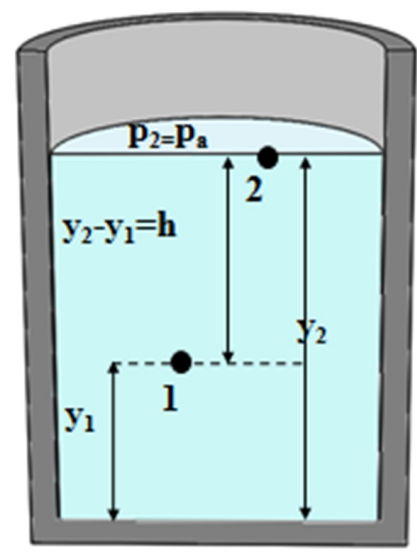

Gambar 2: Zat cair diam dalam wadah terbuka.

Zat cair diam tidak mengalir atau berada dalam kesetimbangan, maka seluruh elemen volumenya juga dalam kesetimbangan. Jika elemen berbentuk lapisan sangat tipis (seperti pada Gambar 1) dengan tebal dy, luas permukaan A dan rapat massa zat cair $\rho$, maka massa elemen itu adalah $\rho$ A dy dan beratnya dw adalah $\rho \mathrm{g}$ A dy. Gaya yang dikerjakan pada elemen tersebut oleh zat cair sekelilingnya dimanapun selalu tegak lurus pada permukaan elemen. Berdasarkan simetri, gaya resultan horisontal pada sisinya sama dengan nol, karena saling menghilangkan [2]. Gaya ke atas pada permukaan bawah adalah pA, sedangkan gaya ke bawah pada permukaan atas adalah $(\mathrm{p}+\mathrm{dp})$ A. Karena dalam kesetimbangan, maka berlaku

$$
\begin{aligned}
\sum F_{y} & =0 \\
p A-(p+d p) a-\rho g A d y & =0
\end{aligned}
$$

sehingga diperoleh

$$
\frac{d p}{d y}=-\rho g
$$

Karena $\rho$ dan g keduanya besaran positif, bila dy adalah positif (tinggi bertambah) akan memberikan nilai dp yang negatif (tekanan berkurang) dan sebaliknya.

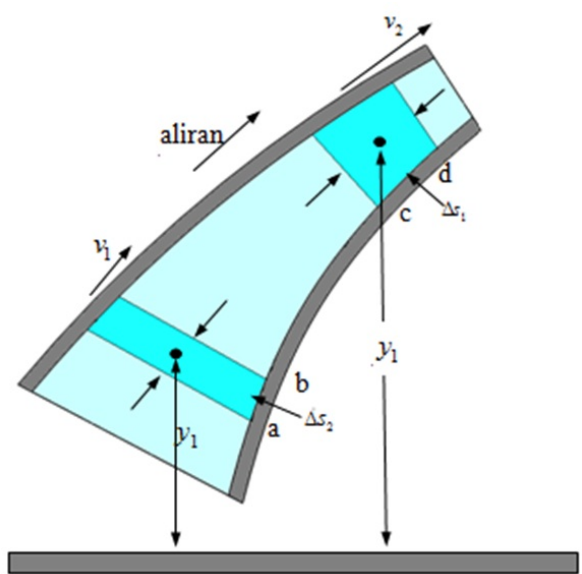

Gambar 3: Usaha netto yang dilakukan terhadap elemen sama dengan pertambahan energi kinetik dan energi potensialnya.

Jika $\mathrm{p}_{1}$ dan $\mathrm{p}_{2}$ adalah tekanan pada tinggi $\mathrm{y}_{1}$ dan $\mathrm{y}_{2}$ di atas suatu bidang acuan, maka integrasi Pers. 3, untuk $\rho$ dan $\mathrm{g}$ konstan, didapat

$$
p_{2}-p_{1}=-\rho g\left(y_{2}-y_{1}\right)
$$

jika persamaan ini diterapkan pada zat cair dalam bejana terbuka seperti pada Gambar 2, bila titik-1 berada pada kedalaman $\mathrm{h}$ dari permukaan atas dan misalkan bertekanan $\mathrm{p}$, sedangkan titik-2 di permukaan zat cair dengan tekanan sama dengan tekanan atmosfir $\mathrm{p}_{a}$, diperoleh

$$
\begin{aligned}
p_{a}-p & =-\rho g\left(y_{2}-y_{1}\right) \\
p & =p_{a}+\rho g h
\end{aligned}
$$

tampak bahwa, tekanan pada zat cair diam adalah sama pada semua titik dengan kedalaman yang sama.

Bila zat cair tidak diam, berarti zat cair tidak dalam kesetimbangan, maka untuk dua titik yang ketinggiannya berbeda, perbedaan tekanan tidak hanya tergantung pada perbedaan ketinggian titik, tetapi juga pada perbedaan antara kecepatan pada masing-masing titik tersebut.

Gambar 3 menggambarkan zat cair tidak mampat mengalir sepanjang pipa yang penampang lintang dan ketinggiannya tidak sama. Tinjau elemen kecil zat cair, bergerak dari titik-1 ke titik-2 yang terletak di sepanjang pipa aliran. Pada titik1 , memiliki ketinggian $y_{1}$ terhadap suatu acuan, dengan kecepatan aliran $\mathrm{v}_{1}$, luas penampang lintang pipa $\mathrm{A}_{1}$, dan memiliki tekanan $\mathrm{p}_{1}$. Hal yang sama berlaku untuk titik-2, yaitu $y_{2}$, $\mathrm{v}_{2}, \mathrm{~A}_{2}$, dan $\mathrm{p}_{2}$ adalah harganya pada titik-2.

Karena zat cair itu mendapat tekanan di semua titik, pada kedua permukaan sisi tegak elemen bekerja gaya-gaya yang mengarah ke dalam, seperti ditunjukkan oleh anak panah tebal. Waktu elemen ini bergerak dari titik-1 ke titik-2, gaya yang bekerja terhadap muka kirinya melakukan usaha positif dan yang bekerja terhadap muka kanannya, melakukan usaha negatif. Usaha netto, atau selisih antara usaha positif dan negatif tersebut, sama dengan perubahan energi kinetik elemen yang bersangkutan ditambah perubahan energi potensial, 


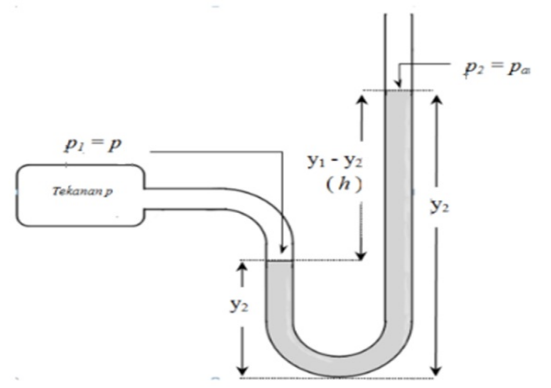

(a)

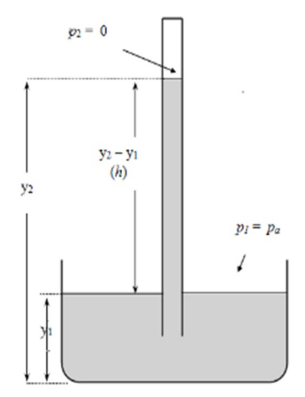

(b)

Gambar 4: (a) Manometer tabung terbuka untuk mengukur tekanan di dalam tangki. (b) Barometer.

sesuai dengan teorema kerja dan energi, maka akan diperoleh persamaan Bernoulli [3]. Kalau persamaan Bernoulli diterapkan pada titik 1 dan titik 2 , serta mengambil dasar tangki sebagai tinggi standar, maka diperoleh

$$
p+\frac{1}{2} \rho v_{1}^{2}+\rho g h=p_{a}+\frac{1}{2} \rho v_{2}^{2}
$$

Pengukur tekanan yang paling sederhana adalah manometer pipa terbuka seperti pada Gambar 4(a). Alat ini berupa pipa berbentuk U yang berisi zat cair. Salah satu ujung akan ditentukan tekanan $\mathrm{p}$ dan di ujung yang lain berhubungan dengan atmosfer [4]. Tekanan pada dasar kolom sebelah kiri adalah $\mathrm{p}$ $+\rho \mathrm{g}_{1}$ sedangkan pada dasar kolom sebelah kanan $\mathrm{p}_{a}+\rho \mathrm{g}$ $\mathrm{y}_{2}$ dengan $\rho$ adalah rapat massa pada monometer itu. Karena tekanan-tekanan tersebut keduanya bekerja terhadap titik yang sama, maka

$$
p+\rho g y_{1}=p_{a}+\rho g y_{2}
$$

dan

$$
p=p_{a}=\rho g\left(y_{2}-y_{1}\right)=\rho g h
$$

Tekanan $\mathrm{p}$ disebut dengan tekanan mutlak, sedangkan selisih $\mathrm{p}-\mathrm{p}_{a}$ antara tekanan ini dengan tekanan atmosfer disebut tekanan relatif atau tekanan pengukur (gauge pressure). Terlihat, tekanan pengukur itu sebanding dengan selisih tinggi kolom-kolom zat cair itu.

Barometer raksa terdiri atas pipa gelas panjang yang sudah diisi dengan raksa lalu dibalik dan dimasukkan ke dalam bejana berisi raksa pula, seperti Gambar 4(b)[3]. Dalam ruang di atas kolom raksa hanya ada uap raksa yang tekanannya

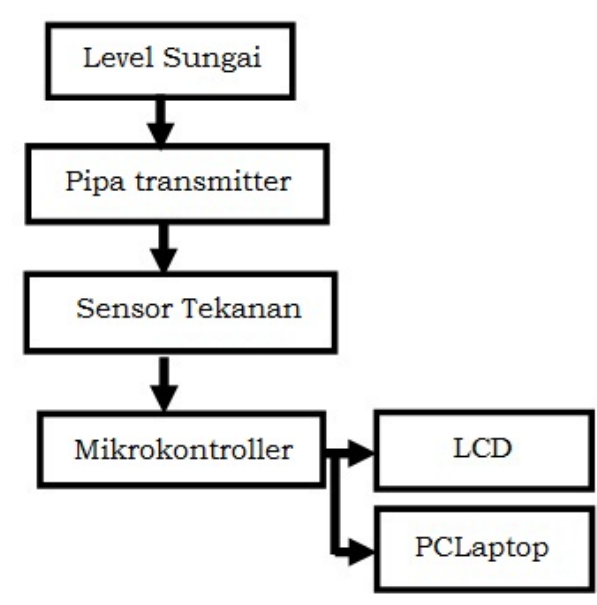

Gambar 5: Diagram blok pengamatan ketinggian permukaan air sungai.

pada temperatur kamar sangat kecil sehingga dapat diabaikan, maka

$$
p_{a}=\rho g\left(y_{2}-y_{1}\right)=\rho g h
$$

\section{METODOLOGI}

Pada penelitian ini digunakan beberapa peralatan dan bahan. Peralatan yang dibutuhkan mencakup perangkat keras (hardware) dan perangkat lunak (software). Adapun perangkat keras yang dibutuhkan dalam penelitian ini berupa mikrokontroller ATmega328 yang diintegrasikan pada board ArduinoUno, satu unit laptop hp (sebagai pemrograman sekaligus pengambilan data serial dari ArduinoUno), Liquid Crystall Display (LCD) (sebagai tampilan nilai yang terukur pada serial computer), pipa digunakan transmiter, power supply (sebagai pencatu pada Arduino), dan sensor BMP085 (sebagai sensor untuk mendeteksi perubahan tekanan).

Seperti tampak pada Gambar 5, prinsip kerja dari alat yang telah dibuat adalah dengan memanfaatkan tekanan dalam zat cair (air sungai) yang semakin besar ketika ketinggian level air sungai meningkat [5]. Tekanan tersebut dialirkan menggunakan pipa transmiter yang tertutup sehingga tekanan zat cair tersebut menekan udara yang ada dalam pipa tertutup berdasarkan prinsip trasmiter pneumatik [6]. Tekanan udara di dalam pipa kemudian diterima oleh sensor tekanan (BMP085) yang kemudian diproses oleh mikrokontroler. Modul mikrokontroler yang digunakan yaitu ArduinoUno. Mikrokontroler kemudian memproses data tekanan menjadi data level ketinggian dan menampilkan data hasil pengukuran pada LCD agar mempermudah dalam proses pengukuran ketinggian permukaan air [7]. Proses pengukuran ketinggian air sungai terlihat pada Gambar 6.

Blok-blok yang dirancang dalam penelitian ini meliputi:

\section{Pipa transmitter}

2. Sensor tekanan, sensor yang digunakan dalam penelitian ini yaitu BPM085. Sensor ini sudah terintegrasi 


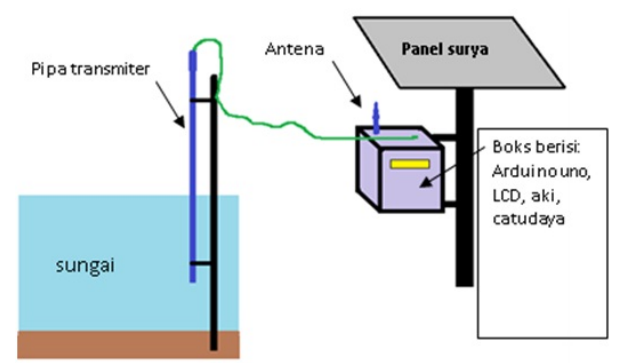

Gambar 6: Sistem Pengukuran Ketinggian Permukaan Air.

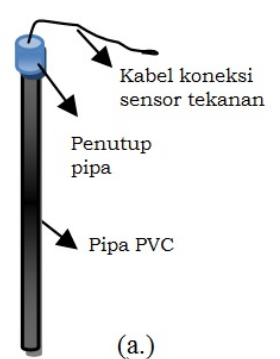

(a.)

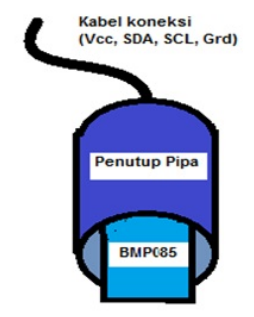

(b.)

Gambar 7: Rancang Bangun: (a.) Pipa Transmiter dan (b.) Tutup Pipa Transmiter.

dalam satu modul BMP085. Modul BMP085 dimasukkan ke dalam pipa transmiter dan diletakkan di ujung yang tertutup. Seperti yang terancang jelas pada Gambar 7. Berdasarkan datasheet, koneksi antar pin I/O dari Arduino dan Modul BMP085 adalah sebagi berikut:

- Pin $\mathrm{V}_{c c}$ padamodul BMP085 dihubungkan dengan pin output $\mathrm{V}$ 3,3 volt pada boardArduinoUno.

- Pin inputGround(Gnd) pada modul BMP085 dikoneksikan dengan Pin Gnd pada ArduinoUno.

- Pin SDA pada BMP085 dikoneksikan dengan Pin 4 (analog) pada BoardArduinoUno.

- Pin SCL pada Modul BMP085 dikoneksikan dengan Pin 5 (Analog) pada BordArduinoUno.

Koneksi Antar I/O Modul BMP085 dengan bordArduinoUno ditunjukkan pada Gambar 8.

3. Mikrokontroler berfungsi sebagai pengendali utama yang dapat mengambil dan mengolah data dari sensor tekanan kemudian menampilkannya di LCD dan memerintahkan SIM900 untuk mengirim ke webserver secara berkala [8]. Dalam penelitian ini digunakan mikrokontroler ATMega328 yang terintegrasi dengan board ArduinoUno yang mempunyai perangkat lunak

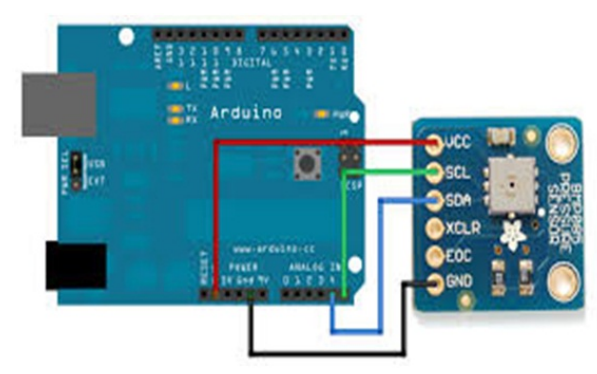

Gambar 8: Rangkaian Sensor BMP085 dengan boardArduinoUno.

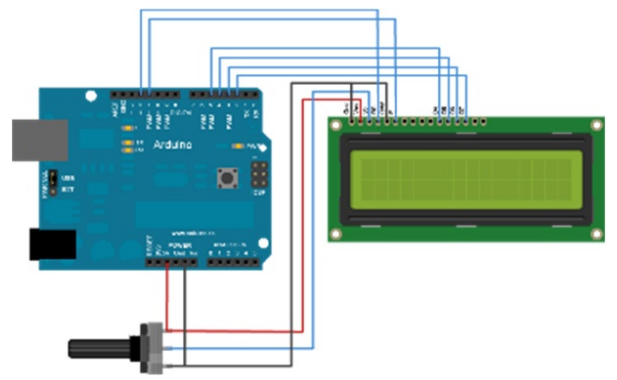

Gambar 9: Rangkaian LCD dengan Arduino.

tersendiri berfungsi sebagai developer program untuk memasukkan program ke dalam mikrokontroler [9]. Pin-pin yang tersedia pada modul ArduinoUno kemudian di koneksikan dengan I/O dari sensor tekanan (BMP085), LCD dan SIM900.

4. Liquid crystal display (LCD) berfungsi untuk menampilkan informasi yang terbaca dari sensor dan dapat dilihat langsung dislokasi, seperti pada Gambar 9.

Setelah semua alat terpasang dengan baik, kemudian dilakukan kalibrasi dan pengujian alat [6]. Pengujian dilakukan di pintu air kali Wonorejo Surabaya.

\section{ANALISIS DATA DAN PEMBAHASAN}

Perancangan dan pembuatan alat ukur ketinggian permukaan air sungai dilakukan dengan pengukuran tekanan di dalam air sungai, kemudian dilakukan kalibrasi dan pengujian alat di sungai.

\section{Pengukuran tekanan di dalam air sungai}

Sensor yang digunakan pada penelitian ini adalah BMP085. Modul BMP085 dipilih karena sesuai dengan kebutuhan dalam penelitian ini yakni mempunyai sensitivitas yang tinggi, konsumsi daya yang rendah, harganya yang terjangkau dan mudah dalam penggunaannya. Setelah rangkaian modul BMP085 dan board ArduinoUno serta koneksi ke komputer terpasang, kemudian dilakukan perancangan software. Pada penelitian ini tekanan yang dibaca oleh sensor adalah tekanan 


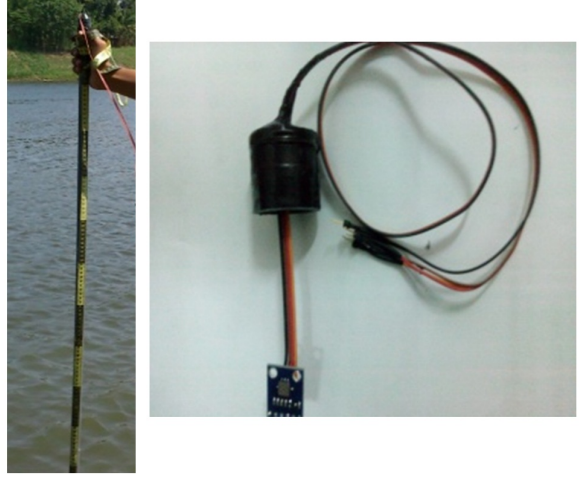

Gambar 10: Pipa transmiter dan sensor tekanan (BMP085).

udara (barometer). Setelah sensor tekanan BMP085 dapat membaca tekanan udara sekitar, maka modul BMP085 dimasukkan kedalam pipa transmiter agar dapat digunakan untuk membaca tekanan dalam air sungai.

Pipa transmiter ini berguna untuk mengubah level ketinggian air sungai menjadi tekanan udara. Karena berdasarkan teori, level ketinggian sungai berbanding lurus dengan tekanan dalam air. Untuk itu perlu dirancang dan dibuat transmiter yang mempermudah pengukuran level berbasis prinsip tekanan dengan menggunakan sensor BMP085. Oleh karena itu, dirancang dan dibuat transmiter berupa pipa dengan prinsip pneumatik. Tekanan didalam air sungai akan memampatkan udara dalam pipa transmiter sehingga tekanan udara dalam tabung meningkat.

Pipa transmiter menggunakan pipa PVC dengan diameter $2 \mathrm{~cm}$ dan panjang $2 \mathrm{~m}$. Selain disesuaikan dengan kebutuhan dilapangan, panjang pipa juga disesuaikan dengan pipa PVC yang tersedia dipasaran. Hal ini juga bertujuan untuk menghindari banyaknya penyambungan pipa yang mengakibatkan rawan kebocoran. Pada ujung atas pipa juga ditutup dengan rapat. Ketika terjadi kebocoran akan mengakibatkan penurunan nilai tekanan udara di dalam pipa meskipun tekanan dalam air sungai tetap. Padahal yang diharapkan adalah tekanan di dalam berubah berdasarkan tekanan dalam air sungai. Hasil perancangan dan pembuatan pipa transmiter dapat dilihat pada Gambar 10.

Pengujian terjadinya kebocoran pada pipa transmiter dilakukan dengan cara memasukan pipa transmiter ke dalam air dan dibiarkan pada level ketinggian tertentu. Kemudian tekanan yang terbaca oleh sensor diamati. Ketika terjadi kebocoran, maka nilai tekanan yang terbaca akan terus menurun. Jika pipa transmiter bocor maka dilakukan perbaikan sampai pipa transmiter benar-benar tertutup rapat dan tidak bocor, dengan demikian sensor BMP085 dapat digunakan mengukur tekanan di dalam air dengan media pipa transmiter. Setelah pipa trasmitter dipastikan tidak bocor dan dapat digunakan untuk mengukur tekanan didalam air, selanjutnya dilakukan kalibrasi.

\section{Kalibrasi ketinggian air}

Kalibrasi pada penelitian ini dilakukan dengan memband-

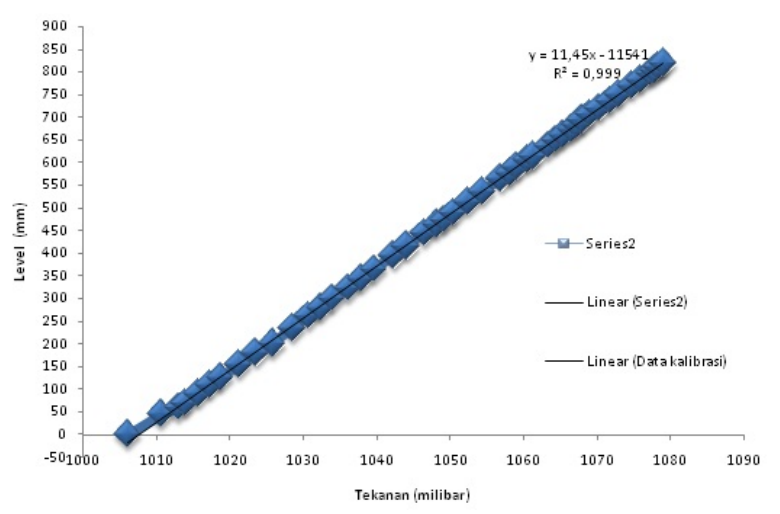

Gambar 11: Grafik hubungan level dengan tekanan pada alat.

ingkan pembacaan pada mistar dengan nilai tekanan yang terbaca oleh alat yang telah dirancang. Mistar kalibrasi ini mempunyai ketelitian $\pm 0,5 \mathrm{~mm}$. Kalibrasi dilakukan di lantai 1 gedung G Jurusan Fisika ITS Surabaya. Sebelum kalibrasi dimulai, pengukuran tekanan atmosfer di lantai 1 gedung $\mathrm{G}$ Jurusan Fisika ITS Surabaya dilakukan terlebih dahulu. Pengukuran tekanan atmosfer tersebut dilakukan sebanyak 5 kali pada tempat yang sama. Rata-rata tekanan atmosfer di lantai 1 gedung G Jurusan Fisika ITS Surabaya yaitu sebesar 1006,14 milibar. Karena tekanan atmosfer di setiap tempat berbeda bergantung ketinggian terhadap permukaan air laut, maka tekanan atmosfer di lantai 1 gedung G Jurusan Fisika ITS Surabaya tersebut menjadi acuan awal.

Kalibrasi dilakukan dengan cara memasukkan air ke dalam bak air sedikit demi sedikit. Setiap level ketinggian permukaan tertentu di ambil data tekanan sebanyak 5 kali. Data yang diperoleh mulai dari level ketinggian 0 sampai ketinggian $819 \mathrm{~mm}$ karena menyesuaikan kedalaman bak air yg digunakan. Ketika level ketingian air 0, tekanan yang terbaca oleh sensor tekanan sebesar 1006,14 milibar dan nilai ini merupakan nilai tekanan udara awal pada pipa transmiter. Setelah mendapatkan hasil data kalibrasi, kemudian dilakukan perbandingan data level ketinggian air sungai dengan nilai rata-rata pengukuran tekanan dari alat yang sudah dibuat dan didapatkan data perbandingan data level dengan nilai rata-rata pengukuran tekanan. Selanjutnya dicari hubungan antara level dengan tekanan pada alat. Setelah itu, dibuat grafik hubungan antara level dengan tekanan yang didapatkan ditunjukkan pada Gambar 11.

Berdasarkan Gambar 11, kurva hubungan level dengan tekanan terlihat tidak linier pada level $\leq 45 \mathrm{~mm}$. Hal ini dikarenakan adanya sedikit air terdorong ke dalam pipa transmiter. Air tersebut diakibatkan oleh tekanan di luar pipa transmiter lebih besar dibanding tekanan di dalam pipa transmiter. Sehingga perubahan level relatif lebih kecil dibandingkan dengan perubahan tekanan. Oleh karena itu, untuk mendapatkan faktor kalibrasi yang terbaik adalah dengan mengambil data kalibrasi pada level $\geq 60 \mathrm{~mm}$. Setelah data kalibrasi tersebut sudah didaptkan, kemudian dibuat grafik hubungan level dengan tekanan pada alat yang terkalibrasi. Grafik tersebut dapat dilihat pada Gambar 12.

Berdasarkan grafik dalam Gambar 12 terlihat bahwa data 


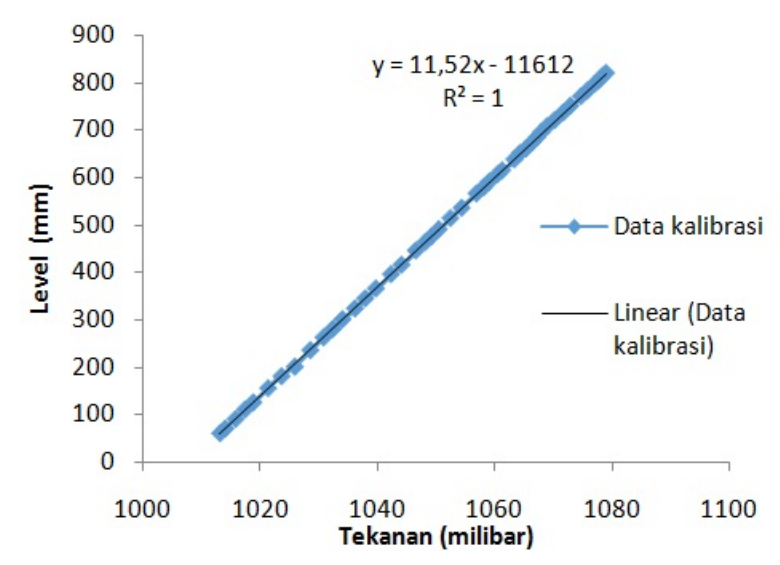

Gambar 12: Grafik hubungan level dengan tekanan pada alat yang terkalibrasi.

yang didapatkan linier. Semakin tinggi level air sungai maka semakin besar nilai tekanannya. Nilai koefisien determinasi pada regresi linier $\left(\mathrm{r}^{2}\right)$ adalah 1 . Maka dapat diketahui bahwa alat yang dibuat mampu melakukan pengukuran level ketinggian air sungai dengan menggunakan prinsip tekanan. Regresi linier yang didapatkan dari grafik yaitu $\mathrm{y}=11,52 \mathrm{x}-11612$, dimana y adalah level ketinggian (level) dan $\mathrm{x}$ adalah tekanan yang terbaca sensor. Persaman linier tersebut merupakan faktor kalibrasi level ketinggian air sungai (h), dimana h dalam satuan milimeter, maka dapat dituliskan sebagai berikut:

$$
\text { Level }=11,52 \times \text { tekanan }-11612
$$

Faktor kalibrasi di atas, kemudian dimasukkan dalam kode program software agar alat ukur dapat digunakan untuk mengukur ketinggian permukaan air.

\section{Pengujian alat ukur}

Setelah didapatkan faktor kalibrasi yang terdapat pada Pers. 8 , kemudian persamaan tersebut dimasukkan kedalam software dan digunakan untuk pengujian nilai level ketinggian. Pengujian dilakukan di laboratorium dan juga di lapangan. Pengujian di laboratorium bertujuan untuk mengetahui karakteristik dari alat ukur yang telah dirancang. Pengujian di lapangan dilakukan di pintu air kali Wonorejo.

Pengujian di laboratorium dilakukan ditempat yang sama dengan pengambilan data kalibrasi, sehingga tidak diperlukan koreksi akibat tekanan atmosfer. Pengujian dilakukan dengan cara membandingkan level mistar dengan level alat yang telah dirancang. Pembacaan level alat dilakukan sebanyak 6 kali. Data yang didapat pada uji laboratorium kemudian perhitungan untuk mengetahui ketelitian dan kecermatan (precition). Pengujian alat dilakukan untuk mengukur level air di dalam bak air. Berdasarkan data uji yang telah diperoleh, terlihat bahwa ada perbedaan nilai pengukuran level oleh alat pada ketinggin permukaan level yang sama namum perbedaan nilai ini cukup kecil. Hasil pengujian ini juga dapat dilihat pada Gambar 13.

Setelah mengetahui unjuk kerja alat ukur yang telah dibuat pada kondisi air tak bergerak atau hidrostatis, kemudian di-

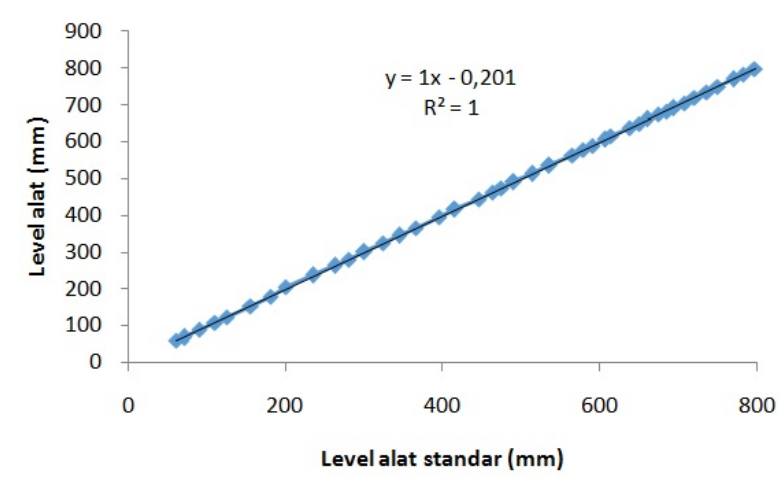

Gambar 13: Grafik hubungan level alat ukur standar dengan level alat ukur.

lakukan pengujian di pintu air kali Wonorejo Surabaya. Pengujian alat dilakukan untuk mengamati kenaikan air pasang di pintu air Wonorejo. Sebelum alat ukur level dipasang, yang dilakukan terlebih dahulu adalah mengukur tekanan antmosfer di pintu air kali Wonorejo. Tekanan atmosfer yang terukur di pintu air kali Wonorejo yaitu 1013,43 milibar, alat ukur level menunjukkan level $63 \mathrm{~mm}$. Pada hal alat ukur belum dipasang, dengan demikian level tersebut menjadi koreksi untuk alat ukur.

Alat ukur dipasang vertikal pada ketinggian awal 1,4 m dari dasar kali. Karena level kenaikan permukaan air akibat pasang surut mulai dari level $1 \mathrm{~m}$ sampai $2,5 \mathrm{~m}$. Pasang surut pada pintu air kali Wonorejo karena terimbas dari pasang surutnya air laut. Pemasangan alat yang cukup tinggi juga bertujuan untuk menghindari lumpur yang dapat mengakipakan tersumbatnya alat ukur. Alat ukur dipasang ditepi sungai dimana lebih dangkal dari tengah sungai.

Adanya perbedaan tekanan atmosfer dan pemasangan alat pada level awal 1,4 m mengakibatkan adanya koreksi untuk faktor kalibrasi alat. Berdasarkan adanya koreksi tersebut, maka faktor kalibrasi alat (persamaan 1) yang diperoleh maka terlihar kelinieran dari pengukuran level dan dapat disimpulkan bahwa alat yang dibuat dapat melakukan pengukuran ketinggian permukaan air di pintu air kali wonorejo faktor koreksi sebagai berikut:

$$
\text { Level }=11,52 \times \text { tekanan }-10149
$$

Persamaan yang diperoleh dimasukkan kedalam software guna untuk akurasi pengukuran.

Pengujian alat di pintu air kali Wonorejo dilakukan 4 kali pada hari yang berbeda. Jika dilihat pada hasil perhitungan kesalahan pengukuran (error) dari pengujian kali ini, kesalahan pengukuran dari alat mencapai 0-9\%. Kesalahan terkecil yaitu $0,02 \%$ pada pengujian ke 4 dan kesalahan pengukuran terbesar pada pengujian ke 3 yaitu sebesar $8,99 \%$. Hasil rata-rata kesalahan pengukuran pada setiap pengujian secara berturut-urut dari pengujian pertama samapai pengujian ke empat yaitu $2,38 \%, 2,8 \%, 3,52 \%$ dan $0,64 \%$. Kesalahan pengukuran terbesar pada pengujian ke 3 karena terjadi gelombang yang cukup besar dan lama karena adanya perahu nelayan yang melewati sungai. Pada pengujian yang pertama dan ke dua juga ada perahu nelayan yang lewat na- 


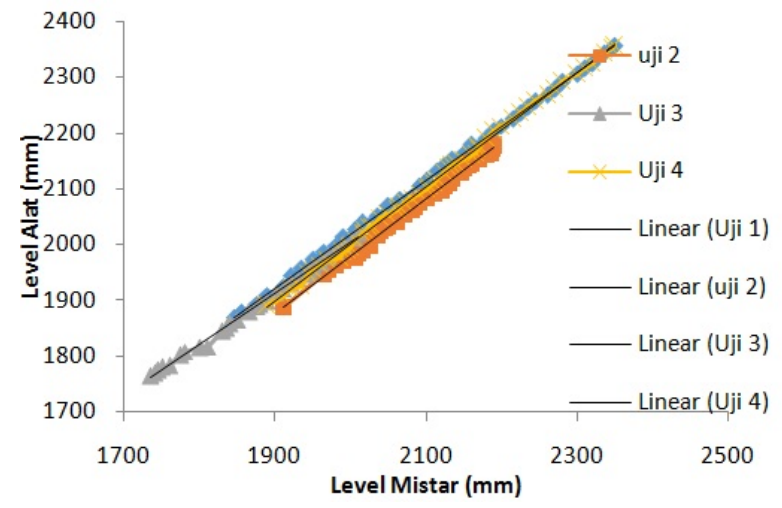

Gambar 14: Grafik hasil pengujian alat ukur level ketinggian sungai di pintu air Wonorejo.

mun tidak sesering pada penguian ke 3 . Pada pengujian ke 4 kesalahan pengukuran kecil karena kondisi sungai cukup tenang, tidak ada perahu yang lewat. Gelombang aliran Air ini berpengaruh karena gelombang aliran tersebut juga membawa energi. Energi tersebut merambat dan mengakipatkan adanya usaha. Usaha ini lah yang menakipatkan adanya gaya dan tekanan pada alat sehingga tekanan yang terbaca bernilai besar padahal level permukaan air rendah. Untuk itu perlu adanya absorber gelombang atau alat lebih cocok digunakan pada aliran laminer.

Data hasil pengujian juga dapat diamati pada Gambar 14
Berdasarkan grafik pada Gambar 14, terlihat bahwa hasil alat ukur yang telah dibuat tetap menunjukkan hasil yang linier dalam 4 kali pengujian di waktu yang berbeda. Perbedaan setiap pengujian lebih kecil dari $4 \mathrm{~cm}$. Perbedaan ini bisa diakibatkan oleh gelombang aliran sungai yang berbeda. Jangka pengukuran setiap pengujian juga berbeda karena menyesuaikan kondisi lokasi dan kondisi alam. Berdasarkan pengujian tersebut dapat di ketahui bahwa alat ukur ketinggian permukaan air yang telah dibuat dapat digunakan dengan baik.

\section{SIMPULAN}

Berdasarkan hasil penelitian pada penelitian maka didapat simpulan sebagai berikut:

1. Sistem sensor level air berbasis prinsip tekanan menggunakan pipa transmiter.

2. Sensor tekanan BMP085 dan pipa transmiter yang dirancang mampu digunakan dengan baik dengan berdasarkan faktor kalibrasi:

Level $=11,52 \times$ Tekanan $-11612 \mathrm{~mm}$.

3. Ketinggian ketinggian permukaan air pasang di pintu air Wonorejo dapat diamati dengan faktor koreksi: Level $=11,52 \times$ Tekanan $-10149 \mathrm{~mm}$.
[1] Armawati, Nuning. 2013. Rancang Bangun Sistem Monitoring Level Air Dalam Proses Pengolahan Air Bersih pada Biosand filter. Surabaya : ITS.

[2] D.C. Giancoli, Fisika (Edisi Kelima, Erlangga, Jakarta, 2001).

[3] D. Halliday, and R. Resnick, Fisika (Jilid 1 Edisi Ketiga, Erlangga, Jakarta, 1990).

[4] F.W. Sears, and M.W. Zemansky, Fisika untuk Universitas 1 (Binacipta, Bandung, 1994).

[5] S. Ginting, Sensor Pyrometer sebagai alat ukur Temperatur, Univ. Andalas, 2009.
[6] A.S. Morris, Measurement and Instrumentation Principles (Butterworth Heinemann, ISBN 0-7506 5081-8, 2001).

[7] https://etd.ohiolink.edu/ap/10?0::NO:10:P10-ACCESSIONNUM:ucin1183994884, waktu akses:6/6/2015 /10:42

[8] http://www.simcom.us/act_admin/supportfile/SIM900HD_V1.01\%28091226\%29.pdf

[9] http://www.jasonvolk.com/wpcontent/uploads/2010/04/mega328p.jpg [10] www.arduino.cc 